\title{
LAS INSTITUCIONES DESDE LA MODERNIDAD KEYNESIANA Y EL NEOLIBERALISMO APUNTES PARA UNA REFLEXIÓN SOBRE LA (LAS) ARTICULACIONES ENTRE LO SOCIAL Y LO SUBJETIVO DESDE LA FIGURA DE CIUDADANIA
}

\author{
Dr. Alejandro Klein \\ Research Affiliate- Oxford Institute of \\ Ageing-Oxford University. \\ alejandroklein@hotmail.com \\ Profa. Dra. Rita de Cássia da Silva Oliveira \\ UEPG
}

\section{Introducción}

Através de este trabajo busco establecer algunas reflexiones sobre cómo se configuran las instituciones dentro de la modernidad estatal o capitalismo keynesiana, hoy en profunda revisión desde las estructuras sociales neoliberales. El análisis no es exhaustivo ni podría serlo. Como se advertirá destaco especialmente sólo algunos puntos a los que me dedico en este momento como parte de mis investigaciones académicas.

\section{Moderinidad Keynesiana: Lazo social indudable- Institucionalidad sólida}

Lewkowicz define al concepto de lazo social como parte fundamental de la modernidad estatal:

El lazo social moderno está basado en la ficción del ciudadano, en la ficción de las naciones, en la historia como donadora de la identidad, en la representación como dispositivo de funcionamiento y fundamentalmente basado en la idea de progreso (...) ficción social que instituye a los individuos como miembros de esta sociedad (Lewkowicz, 2004: 57)

Habría que agregar que este lazo ha sido, más que una ficción (término con el que estoy en desacuerdo), una ilusión eficaz que ha permitido sostener dentro de la modernidad keynesiana, nódulos sólidos que habilitaron una construcción de subjetividad basada en etapas (etarias) preestablecidas, consolidación de un porvenir tangible y a nivel social, la instauración de vínculos basados tróficamente en el reconocimiento de lo ajeno, Mucha cosa como para tratarse de pura ficción...

Por el contrario, el término "ilusión eficaz" me permite sostener una perspectiva que sin desconocer el alcance de lo imaginario, no desdeña realizaciones concretas a nivel de calidad de vida, aspiraciones, esperanzas. Esta doble colusión: imaginario-materialidad, concretó dentro del capitalismo estatal un programa de inclusión visible, sosteniendo un lazo social que no se ponía en duda para ninguna clase social, por más que las divisiones en clases sociales existieron y existen a través de diferentes conflictos y/o lucha de clases.

Desde este imaginario social toda la humanidad era "tierra simbólica" y de allí la importancia del establecimiento de diferentes grados de comunicación social, representados por la calle, los paseos, las plazas recorridas y habitadas por todos los ciudadanos. Se compartía el orgullo de ser ciudadano, de ser "amparado" por leyes adecuadas y por formar parte de la dinámica social ocupada por instituciones justas y soberanas que integraban y socializaban. Como señala A. M. Fernández: 
Las instituciones forman parte de las redes de poder social. En circuitos macro o micro, la institución constituye un factor de integración donde las relaciones de fuerza se articulan en formas: formas de visibilidad como aparatos institucionales y formas de enunciabilidad, como sus reglas (Fernández, 1989: 55).

Esta capacidad de integración se presenta en la modernidad keynesiana como una flexibilidad en la inclusión social, sosteniendo un funcionamiento semipermeable que reproduce modelos sociales pero sosteniendo una subjetividad autónoma. Emiliano Galende señala así al:

Individuo strictu-sensu, como aquel que defiende su papel y valor dentro de la sociedad. Es decir, aquel que siendo gestor de su autonomía, la realiza dentro de los marcos normativos e institucionales (Galende, 1997: 112).

De esta manera, individuo-autonomía e institución se forjan correlativamente. Autonomía debería pensarse como la capacidad de generar conductas inéditas, pero teniendo como base un fondo social de respuestas posibles que pueden ser o no, tenidas en cuenta.

Desde este punto de vista, la institución cumple con un "ya- ahî" desde el cual se puede originar contraste o diferencia. Como señala Kaës, es la necesidad "de encontrar enunciados ya dichos, mitos, leyendas, cuentos, teoría, teología, ideologías, garantes de su propia capacidad de enunciación en el marco de las convenciones y de las referencias percibidas y compartidas" (Kaës,1993: 350). A partir de lo instituyente se genera el material y la posibilidad de la propia capacidad de enunciación, es decir, la capacidad de transformación del psiquismo, pero con la aclaración de que para transformar tiene que haber algo transformable.

Al mismo tiempo, la institución debe poder tolerar la capacidad enunciativa del sujeto, como margen de transgresión al que pueda semantizar como cambio valorable y no como escena temida. De esta manera la institución ha de permitir el cambio pero manteniendo su status de solidez, el que se expresa a través de reglas enunciadas o enunciables: "no pasamos a ser seres hablantes y deseantes sino porque ella [la institución] sostiene la designación de lo imposible: la interdicción de la posesión de la madre institución, la interdicción del retorno al origen y de fusión inmediata" (ídem: 14).

La institución en la modernidad keynesiana cumple entonces básicamente dos funciones: asegura interdicciones e interviene en la construcción de subjetividad a través de la sociabilidad sincrética (Bleger, 1967), que permite resguardar lo no-pensable y la definición de los márgenes posibles de confrontación y de conflicto. La institución asegura un marco de pensamiento: dentro de ella y desde ella se puede pensar. Ahorra el tener que pensar lo irrepresentable, como exige pensar lo representable: "para que ese pensamiento advenga hacen falta un marco apropiado y un aparato de pensar, a los que el sujeto singular contribuye en parte, a condición de que ese marco ya esté allí, pronto para ser inventado" (Kaës, 1993: 16).

Por esto, tanto como exige pensar, garantiza las condiciones de pensamiento, "encapsulando" todo lo que es demasiado perturbante:

Nos vemos enfrentados al pensamiento de que una parte de nuestro si mismo esta fuera de sí, y que precisamente eso que está "fuera de sî" es lo más primitivo, lo más indiferenciado, el pedestal de nuestro ser, es decir, tanto aquello que, literalmente, nos expone a la locura y a la desposesión, a la alienación, como lo que fomenta nuestra actividad 
creadora (...). Es constituyente de los espacios psíquicos comunes que son coextensivos a los agrupamientos de diverso tipo. (Ídem: 16).

Pero habría que agregar que así como vuelca hacia "adentro" lo psicótico, también asegura una actividad de transformación, relacionable a la función revêrie de Bion (1962), por la cual los objetos beta (lo persecutorio-psicótico), pasan a ser elementos alfa (elementos disponibles para pensar, soñar, elaborar):

Este trabajo colectivo de pensar cumple una de las funciones capitales de las instituciones: proponer objetos de pensamiento que tienen sentido para los sujetos a los cuales está destinada la representación y que generan pensamientos sobre el pasado, el presente y el porvenir (Kaës, 1993: 18).

De allí que si bien la institución se perfila como relación violenta y expresión del poder cristalizado, no por eso deja de ser al mismo tiempo, estructurante. Instituye espacios psíquicos comunes ofreciendo la garantía de que más allá de uno, siempre hay un otro. En este sentido, es la base para el reconocimiento del otro como un interlocutor, facilitando el vínculo dialógico.

Paralelamente consolida la noción de tiempo, estableciendo que hay algo que antecede y que continúa desde el pasado y hasta un porvenir, estableciendo un legado y una herencia. El anclaje en el ancestro originario que menciona Kaës (1993) como "invención" del progenitor originario, apunta en este sentido a un contrato narcisistasocial propio de la modernidad, que "anuda" a las generaciones en pactos de continuidad y discontinuidad simultáneamente.

La institución es intrínseca a un movimiento permanente instituyente-instituido, por el que se garantizan marcos o espacios sociales catectizados previamente, pero a los que se adviene inventándolos. Por eso Kaës señala: “(...) cada recién llegado tiene que cargar al conjunto como portador de la continuidad y recíprocamente, con esta condición, el conjunto sostiene un lugar para el elemento nuevo" (ídem: 47).

Se robustece así lo que podría denominar.: "contrato narcisista social", ya que la condición que señala Kaës, anuncia que todo miembro de la sociedad (hijo-ciudadano), tiene garantizado un lugar anticipado de inclusión. Alguien es esperado y "esperable" porque se mantiene un espacio amplio catectizado previamente, al cual, en principio, todos pueden ingresar cumpliendo determinadas condiciones. Una de ellas es compartir ideales comunes a los que se debe transformar y continuar.

Estos espacios de catectización, implican también matrices sólidas de inserción, identificación e intercambio, desde el ofrecimiento de un lugar propuesto por la institución:

Significado por el conjunto de las voces que, antes de que cada sujeto desarrollara un discurso conforme al mito fundador del grupo, cada sujeto tiene que retomar este discurso de alguna manera; es mediante él que se conecta con el Antepasado fundador (ídem: 47).

Este conjunto de las voces es lo que llamo operatoria de investimento del espacio social: cada sujeto se va a sentir parte y gestado por aquél, contribuyendo a su continuidad, "parte interviniente y parte constituyente" (ídem: 17). Esta dimensión metafórica siempre es una posibilidad, ya que "donde está la institución un yo puede advenir", estableciendo una promesa siempre abierta y renovada. Como el mismo Kaës (1993) señala, las instituciones no son sólo expresión de una infraestructura material y social, implican al mismo tiempo, una estructura simbólica a través de la cual ellas se expresan. En este sentido tal como Kaës, creo que: 
La institución no es solamente una formación social y cultural compleja (...) realiza funciones psíquicas múltiples para los sujetos singulares, en su estructura, su dinámica, y su economía personal (...) aseguran las bases de la identificación del sujeto al conjunto social: constituye (...) el trasfondo de la vida psíquica en el que pueden ser depositadas y contenidas algunas partes de la psique que escapan a la realidad psíquica. (Ídem: 25)

Una conclusión fundamental es que un cambio, cualquier cambio, a nivel de las instituciones (y de lo social) no puede dejar de tener repercusiones en lo psíquico y en la forma de construcción de subjetividad. De esta manera:

La identidad no es nunca algo estructurado y definido: se va construyendo. En el seno de las redes de interacción familiares, profesionales y sociales que sitúan a un individuo en el mundo, en cada momento de su vida se construye y reconstruye permanentemente el conjunto de rasgos fundamentales que definen a una persona frente a otra y por los cuales esta persona es re-conocida. Estos rasgos nos son neutros, son valorados, son reconocidos, impregnados de afectividad por los otros en función de las expectativas sociales y de las normas de evaluación que la sociedad se dé (Araujo, 2002: 32).

Hay que decir que las instituciones de la modernidad keynesiana tal como las describe Kaës (1993), no sufren de "complejo de inferioridad" 1: aceptan cambios, confrontación y renovación sin por eso sentirse frágiles o invadidas. La transgresión es tolerada y tal vez alentada como una expresión de la agresividad al servicio del crecimiento (Winnicott, 1972).

Pero la lectura institucional kaësiana no incluye una lectura política, la que permitiría entender que así como la institución es un meta-continente, a su vez hay una meta-institución que es el Estado (Lewkowicz, 2004). Es que en realidad no hay "institución" sino "instituciones". Esta institución es el Estado que organiza y genera un lugar lógico de relación entre todas las instituciones, las que están concatenadas: se pasa de la familia, al jardín, a la escuela, al trabajo, generando un "sendero" de devenir vital (ídem).

De esta manera una de las funciones más importante de las instituciones en la modernidad keynesiana, es generar espacios sociales consensuados al cual advendrán ciudadanos. Desde esta óptica la teoría institucional es inseparable a la teoría de ciudadanía, que es a su vez inseparable de una teoría de la subjetividad. Las instituciones en este tipo de sociedad, son un espacio-tiempo a los cuales se pueden entrar y de los cuales se puede salir, pero en articulación con conductas, actitudes y decisiones. Es una anticipación de ciudadanía inseparable de un porvenir de ciudadanía.

Al mismo tiempo parecen articular un doble proceso instituyente-instituido. Por un lado estas instituciones pre-existen "sólidamente" al individuo para que se pueda formar parte de las mismas: "La institución es el conjunto de las formas y las estructuras sociales instituidas por la ley y la costumbre: regula nuestras relaciones, nos preexiste y se impone a nosotros: se inscribe en la permanencia" (Kaës, 1993: 45). Pero por otro, admiten igualmente procesos de transformación: "No se trata sólo de que la institución tiene que ser estable; el intercambio social y los movimientos que lo acompañan exigen de su función que ella lo estabilice" (Ídem).

Proveen así un marco de seguridad y cotidianeidad en el cual es posible reconocerse y orientarse. De allí que es insuficiente describir a este tipo de institución como depósito de aspectos sincréticos (Bleger, 1967) como si sólo operara a nivel vertical. 
Existe también un nivel horizontal, de lazo social, por el cual se constata una regeneración permanente de aquellos símbolos que hacen a la re-instauración y conservación del lazo social.

Si hay algo que caracteriza al lazo social es justamente su durabilidad, tanto como su capacidad de intersubjetividad. En definitiva, las instituciones de la modernidad keynesiana implantan un lazo social capaz de actividad transformadora sin que la misma se semantice como catastrófica. Así las instituciones generaban malestar, pero el ciudadano podía reconocerse en ellas. Quizás implicaban vínculos de ataque y fuga (Bion, 1979) pero también un espacio de seguridad al cual se podía volver:

La institución tiene que ser permanente: con ello asegura las funciones estables que son necesarias para la vida social y la vida psíquica. Para el psiquismo, la institución está, como la madre, en el trasfondo de los movimientos de discontinuidad que instaura el juego del ritmo pulsional y de la satisfacción. Es ésta una de las razones del valor ideal y necesariamente- persecutorio que asume tan fácilmente (Kaës, 1993: 45).

Pero entonces, la supuesta "eternidad" de estas instituciones no es sólo un instituido reacio al cambio. Es también una necesidad, una ilusión eficaz. Y una de las palabras claves de su funcionamiento es ligazón (Klein, 2006): la institución liga, une, lo que en principio no se podría re-unir cumpliendo una "promesa" de renovación e integración ininterrumpida. Así como exige actividad psíquica, ella misma no puede renunciar a la ligazón incesante:

La institución vincula, reúne y administra formaciones y procesos heterogéneos: sociales, políticos, culturales, económicos, psíquicos (...) gran parte de las cargas psíquicas están destinadas a hacer coincidir en una unidad imaginaria estos órdenes lógicos, diferentes, y complementarios, para hacer desaparecer la conflictividad que contienen (Kaës, 1993: 30-31).

Este modelo de funcionamiento institucional, remite a una especie de formación de compromiso, como un meta-yo negociador y articulador, que liga desde el conflicto. Quizás por eso, Bauman (1999) señala como característica de la modernidad (keynesiana) no la presencia de extraños, sino la de amigos y enemigos, dentro de una lógica de conexiones y posibles encuentros.-

\section{La situación desde el Neoliberalismo}

Cabe aclarar que aunque hay autores que insisten en que no hay ruptura radical entre neoliberalismo y modernidad, creo que sí hay efectos irreversibles desde aquél con respecto a algunos basamentos que hacen a la modernidad keynesiana. Especialmente en lo referente a las promesas generadas desde la modernidad clásica, y el modelo de las instituciones y cuyas interpelaciones ideológicas están presentes en todas las fases del capitalismo con un discurso con efectos organizadores del psiquismo, inclusive en situaciones sociales estructuralmente desfavorables como en el capitalismo liberal.

Se puede indicar como desde esta fase neoliberal del capitalismo (que autores como Giddens denominan de alta modernidad) se verifica un desregulamiento y mundialización de los flujos capitalistas, especulación financiera, debilitamiento del Estado-nación, suspensión de los derechos laborales y sociales conquistados, segmentación del mercado de trabajo, desempleo estructual, crisis fiscal permanente que substituye la gestión keynesiana, hegemonia del mercado (Vasconcelos \& Morgado, 2005). Antunes (1999) señala como representa una crisis estructual del capital, con substitución del padrón 
productivo taylorista y fordista a favor de formas de producción flexibilizadas, com la consiguiente crisis del Welfare State, a partir principalmente del inicio de los años 70. En tal sentido se señala la consolidación de :

Una sociedad heterogénea y fragmentada, surcada por profundas desigualdades de todo tipo- clase, etnia, género, religión, etc.- (...) hay un amplio sector social, un tercio excluido y fatalmente condenado a la marginación y que no puede ser "reconvertido" laboralmente ni insertarse en los mercados de trabajo formales (...) se traduce en desempleo masivo, pobreza extrema, anomia y desintegración social, drogadicción y auge de la criminalidad (Sader,1999:80-81).

Pero hay que destacar cómo el neoliberalismo, a pesar de sus efectos dramáticos y graves (Tavares,1999) (Vasconcelos \& Morgado,2005), sigue manteniendo una vitalidad destacable asentada principalmente en el convencimiento de su papel mesiánico e imprescindible para la sociedad "diseminando la simple idea de que no hay alternativas para sus principios " (Sader,1999: 27).

\section{La presencia del Mercado y el Estado}

Uno de los factores principales que hacen a la matriz económica del neoliberalismo es la predominancia del Mercado (Vasconcelos \& Morgado,2005), que aparece atravesado por fuerzas anónimas e invisibles que hacen que los acontecimientos parezcan producto del caos o el azar y no de factores racionales. Vale decir: los acontecimientos se presentan como un instituido incambiable.

Aquél proyecto de la modernidad keynesiana de una sociedad integrada por seres autónomos y racionales dentro de instituciones sólidas, mediados por el planeamiento público nacional, se substituye por una fantástica utopía de una sociedad donde no entran ni regulaciones, ni leyes ni opacidades ni diferencias a título de una globalización en red que se plantea irremediable :

o Mercado só obedece a uma exigência interna que busca escapar a todo controle externo (...) O que se chama de "dinamismo do mercado" é apenas um doce eufemismo para designar seu lado incoercível (...) Tudo, na rede, se encontra no mesmo plano, existem apenas inter- relações dos atores. Não há mais exterioridade que interioridade. Não há mais transcendência que imanência. $\mathrm{O}$ ternário cede lugar à relação dual (Dofour,2005: 82-86) .

Lewkowicz (2004) denomina "estado de fluido" a esta pérdida de referentes "sólidos" que sostiene un mercado de circulación ininterrumpida e ininterrumpible, para garantizar en realidad la ganancia del capital financiero aún al precio de una ruptura social (Sader,1999) . Desde otro contexto Freud señala cómo la ruptura de la cultura lleva al predominio del individuo más fuerte (Freud,1931). Pero en este caso la ruptura social que ha propiciado el neoliberalismo no ha llevado a la arbitrariedad del individuo singular, sino a la del mercado que "se dirige a un sujeto que sólo tiene derechos de consumidor y no los derechos y obligaciones conferidos al ciudadano " (Duschatzky,2002: 21).

Este mercado si por algo se caracteriza, es por "fuerzas" autorreguladas y no por ciudadanos, exigiendo una hiperadaptación a su dinámica : 
(...) basado en el dogma (o el fantasma) de una autorregulación (...)ide dónde viene esta impresión creciente de vivir atrapados bajo una dominación inexorable, "globalizada", tan poderosa que sería vano cuestionarla, fútil analizarla, absurdo oponérsele y delirante siquiera soñar con sacudirse una omnipotencia que supuestamente se confunde con la Historia? (...) Adaptarse es la consigna. Adaptarse una vez más y siempre. Adaptarse al hecho consumado, a las fatalidades económicas, a las consecuencias de esas fatalidades (Forrester,2000: 7-22).

El Mercado pasa a asemejarse casi, desde el imaginario social, a una Máquina donde todo está programado, previsto (Anzieu,1986) y "naturalizado“

y donde aparentemente todo está excelentemente articulado. Las leyes del mercado de esta manera aparecen como eficaces e inmutables. Ya no son creación de los hombres, por el que entre la sociedad y sus integrantes se instala una nueva geografía (social y psíquica) de desconocimiento (Sassen,1988) y no de inclusión.

Sin embargo aún queda un reducto para encontrar sentido a las cosas, provisto por una cultura dogmática neo -evangélica :

La tendencia a reencontrar ciertas " referencias duras" entre las conductas desarrolladas por los individuos y por los grupos para salir de una situación donde tanto la pérdida de las referencias como la multiplicidad de ellas nos hacen entrar en un universo en el cual las potencialidades persecutorias son innumerables (Enriquez,2001: 75) .

Se trata de una primacía del supuesto de ataque y fuga (Bion, 1979), en relación a una des - simbolización que cobija la aparición de movimientos religiosos de martiz fundamentalista:

(...) a atual dessimbolização do mundo pode perfeitamente se conciliar e até mesmo suscitar - com os violentos retornos de religiosidade fanática. O que teria que provar que "a retirada da religião", tese de Marcel Gauchet que subscrevo, de jeito nenhum impede o retorno de virulentas chamas de religiosidade, muito pelo contrário (Dofour,2004: 116).

Situación que implica la acentuación de un estado de desamparo que se ha vuelto insoportable y frente al cual se buscan defensas resguardantes:

El sujeto siempre intentará reencontrarse con sus objetos omnipotentes, búsqueda que es incrementada por todo estado de desamparo que produzca una resonancia en las huellas dejadas por el desamparo originario, lo que se potencia a nivel de lo colectivo (...)la que se produce cuando el Otro del colectivo fracasa en su función de instancia tercera, y la escena social es ocupada por figuras omnipotentes (que pueden ser doctrinas, ideologías, regímenes) y los sujetos se hallan sin Otro y sin otro, y su espacio psíquico es colonizado por un exceso de realidad (Franco,1998: 3-6). 
¿Cual es la explicación que se instala a partir de esta Máquina que impone crisis, sinsabores y amarguras y un " nunca se sabe qué sucederá"? :

Los enanos, las brujas, los duendes, el diablo, se infiltran en relatos cotidianos adoptando naturalidad (...) A ellos se acude en busca de ayuda para cuestiones mundanas (...) Tienen un estatuto diferente de Dios, a quién sólo se le pide por cuestiones de enorme trascendencia (Duschatzky,2002: 40).

Cabe recordar que desde el capitalismo fordista y keynesiano, mercado y Estado mantienen respectivamente una relación fondo- figura, que se invierte en el neoliberalismo. Si en esta modernidad el mercado está mediado por todo un marco de regulación normativa jurídica, es porque el Estado keynesiano instituirá un basamento al proceso de ciudadanía, la ley y la cultura dialógica.

El neoliberalismo opera de manera inversa: el estado es relegado a un fondo y el Mercado prima como figura. Operación que implica el descrédito del Estado o porque es ( se afirma a vozarrones ) ineficaz o burócrata o porque las leyes que dicta son corruptas. No es como señala Lewkowicz (2004) que el Estado es demolido solamente, sino que entiendo que es denigrado. Esta operatoria de la denigración es fundamental al neoliberalismo y explica el poder de su pregnancia y permanencia, al convencer de su necesaria imprescindibilidad ya que se insiste en que no se debe tener "nostalgia" de una sociedad con tantos errores y características "inadmisibles" ...

Aquel Estado Keynesiano que liga y da sentido a las instituciones (Lewkowicz,2004) dentro de un contrato narcisista que lo aseguraba como ancestro fundador (Kaës,1993) es también un "vigilante" de que las instituciones funcionen como deben. Si desde la modernidad keynesiana la producción de subjetividad es indisociable de lo institucional, al faltar el marco regulador estatal las instituciones se disgregan y pierden su capacidad -fundamental- de producir subjetividad (Lewkowicz, 2004) ${ }^{2}$.

Las instituciones ya no "esperan" a quienes las habiten, perdiéndose referentes de pre-catectización (Aulagnier,1975) fundamentales a la historia del sujeto en tanto integrante de una sociedad (Lewkowicz,2004): "Entramos en la crisis de la modernidad cuando hacemos la experiencia de que las instituciones no cumplen su función principal de continuidad y regulación" (Kaës, 1993: 18).

Sin duda el neoliberalismo necesita aún del Estado por al menos dos motivos: tiene que surgir como garante del pago de la deuda externa (Forrester, 2000) y de ejecutar a los deudores internos, endeudados de forma crónica y permanente. Es decir; es un deudor que nunca puede dejar de estar endeudado. Se entiende así que la plusvalía neoliberal no se genera básicamente por producción de bienes y mercancía (Sader,1999), sino por reproducción de deuda y deudores.

Si lo sólido estatal (Lewkowicz,2004) implicaba un marco desde el cual se reconocía y construía ciudadanía, ley, cultura, responsabilidad y convivencia, lo fluido neoliberal instaura la figura de la impunidad, la transgresión, el extraño y la paranoia. La ley ya no es un referente que cubre y protege a todos, destituida de su lugar de resguardo, situación que se acompaña de una retracción de investimento de espacios sociales potenciales. Para tolerar lo "potencial" hay que sostener el transcurso temporal y lo ambiguo que habilitan la "gestación" del espacio transicional (Winnicott,1981) imposible desde un Mercado que es puro presente eficaz, lo que "fractura" la dimensión temporal.

Consecuencia inmediata es que las instituciones en el neoliberalismo producen integrantes pero no ciudadanos ${ }^{3}$. Tengamos en cuenta que desde la modernidad 
keynesiana el transcurso del pasado, el futuro y el presente consolidan biografía (Aulagnier,1991), lo que a su vez posibilitaba concebir al ahorro como " base de la fortuna", según se decía. Pero si el ahorro es la base de la fortuna ( y de la inversión productiva) es porque se construye a través del tiempo, y para eso se necesita generar un imaginario desde el cual no se sienta desaliento al ir construyendo el ahorro de forma paulatina y gradual.

Asimismo la modernidad expresaba con el "los jóvenes son nuestro futuro", una expectativa de porvenir que socialmente consolidaba una promesa de regeneración permanente. El futuro garantiza al joven que será adulto ,que tiene posibilidades de ciudadanizarse e insertarse socialmente como protagonista efectivo, con lo que adolescencia, futuro y porvenir se entrelazaban recíprocamente.

Las consecuencias no son menores e implican una transmutación en lo que tiene que ver con la matriz de la convivencia social, en el imaginario de cómo la sociedad se percibe a si misma y en la forma de construcción de subjetividad general (Galende,1997).

$\mathrm{Si}$ desde aquella modernidad los ciudadanos pueden plantear una regeneración permanente de la sociedad, la situación neoliberal impone una desciudadanización a la ciudadanización de la modernidad keynesiana (Fraga, 2003). Según Lewkowicz (2004) esta exclusión desligante toma la forma de anulación del lazo social, lo que probablemente incentive angustias de no asignación (Bernard, 1991) a la cual se responde con una reasignación hiperadaptada. Es un proceso ominoso (Freud,1919) por el cual así como compulsivamente hay destrucción del lazo social, compulsivamente se lo busca reinstaurar.

Desde la modernidad keynesiana se entendía que estar socializados es formar parte del lazo social, díada que sin embargo el neoliberalismo quiebra. Estar en sociedad ya no implica estar dentro del lazo social. En este punto la subjetividad pierde características de singularidad y el poder expresarse en primera persona (Galende,1997) afirmándose la heteronomía (Franco,2000), la mitologización social (Castoriadis,1992) y la desarticulación de la experiencia de ser individuo (Galende,1997), con lo que se pierden construcciones esenciales que hacen al vínculo sujeto- sociedad : anulación del portador (ya nadie porta nada), el apuntalante (ya nadie se siente representado en los conjuntos ) y el guardián ( ya nadie quiere o puede cuidar o preservar lo social) (Kaës,1993).

De allí que sugiero que substituye al ciudadano la caracterización del individuo como "engranaje". Si aquél es irremplazable, el engranaje sí lo es. Del ciudadano se espera una actitud activa, participativa y transformadora. Por el contrario del engranaje se requiere un lugar pasivo, sin replica y en definitiva que ocupe un lugar de instituido perfecto. Para garantizar este "borramiento" de la ciudadanía se desarticulan los puntales sólidos del Estado, considerados zonas de resistencia y regulación. Se "demuelen" además las figuras de institucionales de ciudadanía propias de una sociedad de empleo, como la del trabajado, substituyéndose la posibilidad de trabajo por el neo-desempleo (Castel,1997). Situación de no- trabajo permanente y estructural en contraste con el desempleo, interregno accidental y transitorio de la modernidad keynesiana. En este sentido el neoliberalismo propicia características de "saqueamiento" de productividad, con anulación de la diferencia trabajo-descanso, que desde la modernidad se expresa como vaivén entre el trabajo y la vuelta al hogar, diferenciando el espacio de rendimiento del espacio de descanso.

De esta manera se aniquilan o pervierten "los sistemas imaginarios y simbólicos predispuestos en las instituciones sociales y transgeneracionales" (Puget,1991: 144). Esto facilita la resignación y el no cuestionar las cosas, como "ley de la obediencia debida", en consonancia con la consolidación del funcionamiento mental alrededor de certezas dogmáticas. 
Concomitántemente la figura del vecino es substituida por la del "extraño", revestido con características de amenaza, indefinibilidad y desresponsabilización social (Bauman,1999). Esta situación que incrementa lo paranoico, imposibilita la confrontación social y generacional (Winnicott,1972) ${ }^{4}$, corroyendo la "confianza" como metaorganizador de las relaciones sociales.

Es posible pensar así que al igual que en épocas de dictadura, el modelo neoliberal "desarticula los fundamentos del conjunto social y destruye las formaciones y los procesos de la vida psíquica que se apuntalan sobre el conjunto social" (Puget.1991:145). Una de esas formaciones es la cultura de diálogo, substituida por un mesianismo de la violencia que lleva a que se "apriete" el espacio entre los hombres como señala Hanna Arendt (Gómez Ramos,2003). Desde aquí sería posible repensar las figuras de violencia que surgen de forma esporádica y brutal ya no como "accidentes" al tejido social sino como parte inherente de una forma de funcionamiento institucional, social y subjetiva.-

Bibliografía

ANTUNES, R. Crisis capitalista contemporánea y las transformaciones en el mundo del trabajo In: Capacitaçao em serviço social e politica social: Modulo 1. Brasilia: CEAD, 1999. AULAGNIER, P. La violencia de la interpretación. Del pictograma al enunciado. Argentina, Amorrortu, 1975.

AULAGNIER, P. Construir (se) un pasado. Argentina, Revista de APdeBA Vol XIII-N ${ }^{\circ}$ 3,1991.

ARAUJO, A. (org.) Impactos del desempleo. Transformaciones en la subjetividad. Montevideo, Alternativas, 2002.

BAUMAN, Z. Modernidade e Ambivalencia. Brasil, Jorge Zahar Editor, 1999.

BERNARD, M. Introducción a la lectura de la obra de René Kaës. Argentina, Asociación Argentina de Psicología y Psicoterapia de Grupos, 1991.

BION, W. R. Experiencias en grupo. Argentina, Paidós, 1979.

BION, W. R. Aprendiendo de la experiencia. Barcelona, Argentina, Paidós, 1962.

BLEGER, J. Simbiosis y ambigüedad. Argentina, Paidós, 1967.

CASTEL, R. Las metamorfosis de la cuestión social. Una crónica del salariado. Argentina, Paidós, 1997.

CASTORIADIS, C. A criação histórica. Brasil, Artes e ofícios, 1992.

DUSCHATZKY, S et al. Chicos en banda. Los caminos de la subjetividad en el declive de las instituciones. Argentina, Paidós, 2002.

DUFOUR, D. R. A arte de reduzir as cabeças. Sobre a nova servidao na sociedade ultraliberal. Brasil, Companhia de Freud Editora, 2005.

FERNANDEZ, A. La dimensión institucional de los grupos. In: Lo Grupal 7. Argentina, Búsqueda, 1989.

FORRESTER, V. Una extraña dictadura. Argentina, Fondo de Cultura Económica, 2000. FRAGA. et al. Jovens en tempo real. Brasil, DP\&A editora, 2003.

FRANCO, Y. Más allá del Malestar en la Cultura. Argentina, www.topia.com.ar/articulos/25masal.htm, 1998.

FRANCO, Y. Subjetividad: lo que el mercado se llevó.(Una perspectiva desde el pensamiento de Cornelius Castoriadis). Buenos Aires, www.magmanet.com.ar/subjetividad.htm , 2000.

FREUD, S. Lo ominoso. Argentina, Amorrortu Vol. XVII, 1919. 
GALENDE, E. De un horizonte incierto, psicoanálisis y salud mental en la sociedad actual. Argentina, Paidós, 1997.

GOMEZ RAMOS, A. Totalitarismo, historia y banalidad del mal. España, www.uc3m.es/uc3m/dpto/HC/AGR/totalitarismo.html, 2003.

KAËS, R. Realidad Psíquica y sufrimiento en las Instituciones. Argentina, Paidós, 1993.

KLEIN, A. Adolescencia, un puzzle sin modelo para armar. Uruguay, PsicolibroWaslala, 2004.

KLEIN, A. Adolescentes sin adolescencia: Reflexiones en torno a la construcción de subjetividad adolescente bajo el contexto neoliberal. Uruguay, Psicolibro- Universitario, 2006

LEWKOWICZ, I. Pensar sin estado. La subjetividad en la era de la fluidez. Argentina, Paidós, 2004.

LEWKOWICZ, I. et al Del fragmento a la situación. Notas para la subjetividad contemporánea. Argentina, Gráfica México, 2001.

LEWKOWICZ, I. Pensar sin estado. La subjetividad en la era de la fluidez. Argentina, Paidós, 2004.

PUGET, J. \& KAES, R. Violencia de estado y psicoanálisis. Argentina, Centro Editor de América Latina, 1991.

SADER, E. \& GENTILI, P. (org) La trama del neoliberalismo. Mercado, crisis y exclusión social. Argentina, Universitaria de Bs. As., 1999.

TAVARES, L. Os custos socias do ajuste neoliberal no Brasil. Chile, FLACSO, 1999.

VASCONCELOS, E. \& MORGADO, R. Subsídios analíticos e metodológicos para a atuação no Sistema Único de Assistência Social (SUAS), e do Programa de Atendimento Integral à Familia. Brasil, (PAIF/SAS/RJ), 2005.

WINNICOTT, D. Realidad y Juego. España, Gedisa, 1972.

WINNICOTT, D. El proceso de maduración en el niño. España. Laia, 1981

Artigo recebido em: 15/05/2009

Aprovado para publicação em: 10/06/2009

\footnotetext{
${ }^{1} \mathrm{Y}$ esta es una diferencia fundamental en cómo se estructuran las instituciones dentro del neoliberalismo de mercado

${ }^{2}$ En realidad habría que decir mejor que se trata de "otra" subjetividad.

${ }^{3}$ Cabe aclar que esta distinción funciona en el plano ideológico e imaginario, pero poco en el plano socio-histórico concreto.

${ }^{4}$ Tanto como la capacidad de rebeldía, disconformidad y reenigmatización (Klein, 2004).
} 